\title{
DESENVOLVENDO O PENSAMENTO ABSTRATO NO ENSINO DE FÍSICA POR MEIO DO LABORATÓRIO ABERTO
}

\author{
José Galúcio Campos ${ }^{1}$
}

\section{RESUMO}

Este trabalho é um ensaio em que são apresentados resultados positivos sobre o desenvolvimento da habilidade cognitiva de pensamento abstrato, no ensino de Física, por meio do laboratório aberto. Para tanto realizou-se uma pesquisa qualitativa do tipo pesquisa-ação (aproximadamente), na qual se utilizou diversos instrumentos de coleta e análise de dados. Os sujeitos da pesquisa foram os alunos do 20 ano do Ensino Médio integrado, professores de Física, coordenadores e chefes de departamento.

Palavras-chave: Ensino de Física. Metodologia de ensino. Ensino por investigação. Laboratório aberto.

\section{DEVELOPING ABSTRACT THINKING IN PHYSICS TEACHING THROUGH OPEN LAB}

\section{ABSTRACT}

This paper is an essay presenting positive results on the development of the cognitive ability of abstract thinking in the physics teaching with the open lab.For this purpose, it was made a action research (approximately) using a several instruments of data collection and data analysis. The subjects of the research were the students of the 2nd year of integrated high school, physics teachers, coordinators and department heads.

Keywords: Physics teaching. Teaching methodology. Inquiryteaching. Open lab.

Recebido em: 8/8/2019

Aceito em: 20/3/2020 
Dado o ocaso do recrutamento das novas tendências pedagógicas na atualidade, busca-se, em geral, a utilização de metodologias de ensino-aprendizagem pouco estruturadas visando-se a, mais que a aprendizagem conceitual, o desenvolvimento de habilidades procedimentais e intelectuais, se não, também, o favorecimento da autonomia do aluno para com o processo de aprendizagem.

Em atenção a essas demandas e com as especificidades de uma educação científica, este escrito apresenta resultados preliminares advindos de um trabalho de Doutoramento sobre o desenvolvimento de uma importante habilidade cognitiva para o ensino de Física: o pensamento abstrato.

Para tanto, esta habilidade cognitiva foi desenvolvida por intermeio de uma metodologia pouco estruturada: o laboratório aberto. O laboratório aberto é uma das possíveis metodologias do ensino por investigação.

Em adição, e com fins de concordância teórica, pôs-se o laboratório aberto sob a égide do modelo pedagógico construtivista, pois por meio deste contempla-se mais adequadamente os papeis do professor e do aluno ante o processo de ensino-aprendizagem de modo a satisfazer as exigências desta metodologia em particular.

Justificamos tais escolhas por dupla constatação. A primeira deve-se ao crescimento de publicações no ensino das ciências que se utilizam do ensino por investigação nos últimos 10 anos. Segundo, como crítica. Nota-se que existe um grande apelo à utilização de metodologias que se apoiam no exemplo concreto e familiar para ensinar ciências, em especial a Física.

Haja vista, entretanto, a capacidade cognitiva dos estudantes do Ensino Médio, entende-se que as metodologias, mais que apresentar a Física como uma coleção de resultados particulares, deveriam, em sua maioria, favorecer, judiciosamente, o desapego a situações concretas buscando assim a universalização, por definição, dos conceitos, teorias, leis e objetos da Física.

Em primeira instância, portanto, desenvolver habilidades cognitivas constitui-se em uma demanda urgente. Desta forma defende-se a seguinte tese: é possível desenvolver o pensamento abstrato por meio do laboratório aberto.

Buscando averiguar a tese supra fez-se uma pesquisa qualitativa do tipo pesquisa-ação (em aproximação) valendo-se de diversos instrumentos de coleta e análise de dados. Os sujeitos da pesquisa foram alunos do 2- ${ }^{a}$ ano do Ensino Médio de uma escola pública da rede federal de ensino na cidade de Manaus.

Ressalta-se que os resultados iniciais acenam positivamente para confirmação desta tese.

Cabe esclarecer, todavia, em razão da própria natureza do ensino por investigação e da dificuldade de se medir objetivamente as atividades do pensamento, trabalhos que compartilham das mesmas características que este aqui apresentado estão sempre sujeitos a refinamentos teóricos e a ajustes metodológicos. Logo, tome-se este texto como um ensaio.

Tome-se nota, porém, de que, muito embora os resultados sejam preliminares, devido ao cuidado teórico e à busca pela rigorosidade metodológica, chegou-se a um ponto em que se deseja compartilhá-los. 


\section{BASE TEÓRICA}

O ensino por investigação é uma abordagem didática que emergiu como crítica ao modelo educacional do início do século 20 e é de praxe considerar que tal modelo chamado aqui de tradicional - apresente as seguintes características: o professor é uma figura de autoridade, ensino meramente livresco, a metodologia investia maciçamente em memorização, e o aluno não tinha liberdade para aprender da forma mais adequada para si (TRÓPIA, 2011; RODRIGUES; BORGES, 2008; ZÔMPERO; LABURÚ, 2011).

À gama de metodologias de ensino-aprendizagem vinculadas ao ensino por investigação chamaremos de atividades investigativas. Todas elas trazem consigo alguns pontos convergentes, quais sejam: elas começam com uma situação-problema que deve ser contextualizada e ter relação com algum problema científico; a outra é sobre o aspecto prático: no ensino de ciências por investigação ensinamos por meio de atividades práticas com o fim de resolver problemas modelando-se as etapas realizadas pelo cientista diante da produção do conhecimento (CARVALHO, 2014; MUNFORD; LIMA, 2007; RODRIGUES; BORGES, 2008).

Não esperamos que o exposto no parágrafo anterior seja uma definição. Absolutamente. A literatura é taxativa ao pontuar que a atribuição de sentido que o termo recebe de professores, educadores, pesquisadores da educação é diversa e mudou várias vezes devido às grandes reformas educacionais ocorridas nos Estados Unidos e na Europa (TRÓPIA, 2011). O que se tem à disposição são os pontos convergentes que as diferentes atividades investigativas contemplam (FERREIRA et al., 2010); mas não há uma definição objetiva dela.

Não cabe neste ensaio explorar as diferentes possibilidades de conceituar ou definir objetivamente as atividades investigativas; mas antes, cabe sim estabelecer os pressupostos que norteiam nossa prática docente ante esta abordagem didática.

Primeiro, modelamos as etapas de trabalho do cientista adaptando-as à realidade do contexto escolar. Não esperamos que o aluno (re)construa conhecimento científico algum, pois não entendemos, no contexto deste ensaio, que as atividades investigativas sejam uma espécie de pedagogia da redescoberta (GASPAR, 2014). O conhecimento científico trabalhado nas escolas já está construído e já é consensual (CHEVALLARD, 1991), restando ao professor ensinar e/ou criar condições para que os alunos aprendam-no utilizando meios que mais se adéquam as suas necessidades, mas envolvendo-os em atividades que Ihes exigem engajamento; as investigações são adequadas a este fim.

Em segundo, o modelo pedagógico que consideramos mais interessante para lidar com as atividades investigativas é o construtivista, pois colocamos o aluno em um processo de ensino-aprendizagem que admite a possibilidade de estruturação das atividades didáticas por parte do professor (mediação), é um processo dialogal (dialética aluno-objeto-professor), permite ao aluno conquistar autonomia ante a aprendizagem e a aquisição de conhecimento ao longo do processo (BECKER, 2013).

Evidentemente que ao final do processo o aluno deve indicar proximidade entre o conhecimento adquirido e o conhecimento científico consensual. Somos avessos ao entendimento de um construtivismo como sinônimo de aprendizagem espontânea, im- 
portando, verdadeiramente, a atribuição de sentido que o aluno dá ao conhecimento em vez do conhecimento de per se. Isto, a nosso ver, contribui mais para sofisticar o senso comum do que ensinar ciências. É inegociável - no contexto deste ensaio - aproximar o saber aprendido com o saber científico de referência (CHEVALLARD, 1991).

Em terceiro lugar, tem-se a máxima cognitivista de que o desenvolvimento de habilidades não precede a aquisição de conhecimentos factuais (WILLINGHAM, 2011; SOUZA; VALENTE, 2014). Com isto pretendemos evitar a sobrecarga cognitiva - ou desenvolvemos habilidades ou ensinamos conceitos. Desenvolver habilidades que para tanto necessitam de conhecimento factual não nos parece razoável, todavia não negamos esta possibilidade. Este é um posicionamento relativo ao nosso modo de trabalhar, preferencialmente.

As atividades investigativas consistem em resolver situações-problemas que não devem ser solucionadas automaticamente (imediatamente). Aprender sobre um problema ao mesmo tempo que se tenta resolvê-lo traz muitas complicações para a execução da atividade quando vista de per se, além de complicações no tempo didático. Não é pragmático.

Toma-se nota de que ensinar e aprender diz respeito a duas dimensões; quais sejam: questão conceitual (fatos científicos) ou desenvolver habilidades (competências) procedimentais e/ou intelectuais (CARVALHO, 2014; SUART et al. 2010). Recentes pesquisas, no entanto, relatam que as atividades investigativas são mais eficientes em desenvolver habilidades do que reforçar aprendizagem de conceitos (WILCOX; LEVANDOWSKI, 2017).

Já foi mencionado que as atividades investigativas são metodologias diversas; neste ensaio colocamos a nota em uma delas: o laboratório aberto (CARVALHO, 2014). Esta metodologia distingue-se do laboratório tradicional, pois é menos estruturada (BORGES, 2002). O aluno não recebe um roteiro dizendo-lhe como deve proceder, inclusive relacionando os equipamentos que deve utilizar no experimento (CARVALHO, 2014).

Assim sendo, após tomar conhecimento da situação-problema, o aluno deve procurar solucioná-la por meio de um experimento feito ao modo que lhe convém: o aluno deve decidir fazê-lo e resolver que materiais serão utilizados.

Neste ensaio usamos o laboratório aberto com o fim de desenvolver habilidades cognitivas (SUART et al., 2010) ou habilidades intelectuais (ou de pensamento).

A motivação para trabalhar com atividades didáticas pouco estruturadas que favoreçam o desenvolvimento de habilidades origina-se do seguinte posicionamento crítico de nossa parte: em geral, as metodologias de ensino-aprendizagem dispensadas ao ensino das ciências, em especial a Física, sempre apelam para situações concretas.

É algo quase que consensual entre professores e pesquisadores do ensino das ciências que se deve diminuir a abstração dos conceitos e entes científicos por meio de exemplos concretos (WILLINGHAM, 2011; POZO; CRESPO, 2009). Concordamos que este é um bom começo. 
No Ensino Médio, entretanto, os alunos têm idade entre 14 e 17 anos, em média, já estão com sua estrutura cognitiva pronta para resolverem situações mais complexas e de raciocinar em abstrato de modo a poder estabelecer relações entre o real e o possível (CLOUTIER; DRAPEAU, 2012).

Entendemos que a meta é se desvencilhar do concreto pelos seguintes motivos: (1) no aspecto formal, a ciência aplica-se ao universal e não somente ao particular (REALE, 2002); (2) a concretização de exemplos no ensino de ciências passa a mensagem de que leis e teorias se aplicam a casos particulares, comprometendo, assim, a aprendizagem científica em longo prazo (CRATO, 2010).

Logo, desenvolver habilidades cognitivas no contexto escolar, no âmbito do Ensino Médio, é uma demanda urgente, em nossa concepção. Feitas esta consideração crítica e a exposição dos pressupostos das atividades investigativas que serão atendidas neste ensaio, passamos, agora, para a próxima etapa, que consiste em indicar e definir qual habilidade cognitiva interessa para este estudo.

As habilidades cognitivas correspondem a um vasto espectro de possibilidades. Sabemos, no entanto, que existem umas que exigem menos demanda cognitiva do que outras, e, desse modo, há uma hierarquia a se observar entre elas (COSENZA; GUERRA, 2011).

A habilidade cognitiva de interesse é o pensamento abstrato. Entenda-o, aqui, como uma complexa habilidade cognitiva que indica a capacidade do indivíduo de vivenciar situações reais por meio da imaginação. Assim, pensamento abstrato e imaginação comungam, embora sejam processos diferentes, como veremos na sequência.

A definição anterior adveio da reflexão sobre os dois termos que compõem esta habilidade cognitiva: pensar e abstrair. Antes, porém, o que distingue pensamento de imaginação?

Respondemos: imaginar é o processo cognitivo de ver, sentir algo em nosso eu interior como imagem ou representação sem o uso de nossa aparelhagem sensorial; é um desenho impresso em nossa mente (imagem) como uma singularidade parecida com a mesma figura vista com os olhos do corpo (ALVES, 2011).

O pensar, por seu turno, é outro modo de ser que não a imaginação. O pensar permite o acesso ao sentido e à significação (ALVES, 2011), é o conhecer por meio de conceitos (JAPIASSÚ; MARCONDES, 2001). Essas características são muito relevantes ao contexto escolar, especialmente para o ensino das Ciências, como a Física, por exemplo. Por este motivo, prefere-se manter o termo pensar em detrimento de imaginar.

De acordo com o Dicionário de Filosofia, abstração como o ato de abstrair é a atividade do espírito que isola, para considerá-lo à parte (JAPIASSÚ; MARCONDES, 2001). Segundo Santos $(2013,2017)$, abstrair é a capacidade do sujeito de olhar para as partes individuais do todo (análise) para depois recompô-la por meio de conceitos que a tornam universais (síntese).

Então, como podemos constatar, para abstrair recrutamos duas habilidades cognitivas: análise e síntese. Interessante notar o quanto análise e síntese se opõem (JAPIASSÚ; MARCONDES, Idem), todavia concorrem para formar a mesma habilidade cognitiva - o pensamento abstrato. 


\section{METODOLOGIA}

Esta metodologia desenvolveu-se por meio de uma pesquisa qualitativa do tipo pesquisa-ação (GIL, 2010; SAMPIERI et al., 2013; THIOLLENT, 2011) em aproximação, uma vez que nem todos os seus pressupostos foram satisfeitos. Os sujeitos da pesquisa foram alunos do 2 o ano do Ensino Médio - com 16 anos em média - professores, coordenadores e chefes de departamentos.

O local em que a pesquisa ocorreu foi uma escola da rede pública federal de ensino na cidade de Manaus, Estado do Amazonas. O tempo de observação foi de dois anos, o que corresponde ao período escolar (integral) dos anos de 2016 e 2017.

Empregamos ao longo da investigação diversos instrumentos de coleta e análise de dados; quais sejam: observação participante, questionário com perguntas fechadas e do tipo Likert, entrevistas semiestruturadas individual e de grupo (GIL, 2010; SAMPIERI et al., 2013); para análise das entrevistas utilizou-se duas técnicas de codificação qualitativa: a contagem de palavras repetidas (LÜDKE; ANDRÉ, 2015) e a análise linha por linha (SAMPIERI et al., 2013).

Apresentamos, em seguida, as três fases distintas, porém concorrentes entre si, que utilizamos para alcançar o objetivo da pesquisa.

\section{Fase exploratória}

Buscamos atender a três metas nesta fase, ou seja: buscar por uma metodologia de ensino-aprendizagem que mais se adequasse às necessidades dos alunos, determinar em que modelo pedagógico esta tal metodologia deveria ser inserida e qual habilidade cognitiva deveria ser desenvolvida.

Com o objetivo de alcançar as duas primeiras metas tivemos conversas informais com 2 coordenadores de curso e 2 chefes de departamento. Ademias, procurando ainda pelo cumprimento das três metas entrevistamos 80 alunos (2 turmas do segundo ano do Ensino Médio) e 3 professores de Física. Aos alunos, além da entrevista, aplicamos um questionário tipo Likert. E, por fim, lemos 5 projetos pedagógicos dos cursos (PPC) do Ensino Médio Integrado. A leitura dos PPCs foi importante para o cumprimento da terceira meta. Todas as entrevistas, as conversas informais e o questionário tipo Likert concorreram para determinar qual habilidade seria desenvolvida e qual metodologia e modelo pedagógico seriam empregados. Como veremos mais adiante o resultado foi desenvolver o pensamento abstrato com o auxílio da metodologia de laboratório aberto por intermédio do modelo construtivista de ensino-aprendizagem.

Devido ao montante de dados coletados e ao grande volume de entrevistas a serem transcritas, fizemos o seguinte recorte: os resultados deste ensaio dizem respeito somente à turma 21 - com 40 alunos.

Uma vez estabelecido que o problema seria de ordem metodológica fizemos, ao longo do primeiro ano de observação, com que os alunos vivenciassem as aulas de Física a diferentes metodologias de ensino-aprendizagem usando-se variados modelos pedagógicos. Ressaltamos que ao início de cada aula os alunos receberam orientação quanto ao tipo de metodologia e modelo pedagógico que seria empregado. 
Para tanto, utilizamos os modelos pedagógicos diretivo ou explícito (GAUTHIER et al., 2011), o modelo dialogal (BECKER, 2013), e, o não diretivo com a sala de aula invertida (BECKER, 2013; BERGMANN; SAMS, 2016). Observe-se que com os dois primeiros modelos trabalhamos tanto com aulas teóricas quanto as práticas de laboratório. Para um rápido e maior esclarecimento sobre estes modelos pedagógicos sugerimos a leitura de Becker (2013).

\section{Fase empírica}

Dispensamos 8 aulas para esta fase empírica. Cada aula teve duração de 50 minutos. Para as turmas do 2 ano Ensino Médio havia, por semana, duas aulas de Física. Cumpre esclarecer que anterior à coleta de dados fizemos, sempre, uma atividade didática semelhante com a turma participante, pois afinal, foi desejo da nossa parte que durante o processo de observação para a coleta de dados houvesse interferência mínima de sua parte.

Neste sentido, dado o quantitativo de 40 alunos, decidimos que, para melhor observar o comportamento da turma, deveríamos dividi-la em duas. Então, de 8 aulas, cada aluno participou de 4 atividades didáticas realizadas em grupos.

A atividade didática relativa à pesquisa empírica consistiu na proposição de uma questão-problema que deveria ser respondida via experimento. Os alunos propuseram hipóteses para explicá-la, verificaram suas hipóteses por meio de dados coletados pelo experimento e socializaram suas resoluções com os demais colegas e conosco.

Na socialização é (foi) importante dar-se conta de que este é um momento para ajustes conceituais, caso haja necessidade; no contexto deste ensaio surgiu a necessidade de que estes ajustes fossem feitos. Isto foi de tal sorte que uma nova rodada da mesma atividade investigativa foi refeita com a turma.

Ressaltamos que as hipóteses e as soluções elaboradas pelos alunos foram classificadas de acordo com as seguintes categorias (KASSEBOEHMER; FERREIRA, 2013):

a. Hipótese/solução coerente: são aquelas que cumprem o enunciado da situação-problema, claramente, e se fundamentam em fatos científicos e/ou fatos advindos do experimento.

b. Hipótese/solução pouco coerente: há duas possibilidades: em uma ela atende ao enunciado do problema, mas apresenta erros conceituais; na outra, não comete erros conceituais, mas não atende ao enunciado do problema.

c. Hipótese/solução não coerente: apresenta a total falta de nexo entre pergunta e resposta.

\section{Fase analítica}

A etapa final da metodologia empregada teve o objetivo de refletir sobre o trabalho realizado nas etapas anteriores, o que é de praxe da pesquisa-ação como destacado por Thiollent (2011). Esta prática fez com que, por duas vezes fizéssemos ajustes no roteiro das entrevistas, no questionário tipo Likert, nos procedimentos da pesquisa empírica e repensássemos nossas hipóteses iniciais para solucionar o problema que nos propusemos a fazer. 
Os resultados que apresentamos correspondem ao terceiro ciclo de atividades investigativas realizado com esta turma.

\section{RESULTADOS E DISCUSSÃO}

Dado que cada fase da pesquisa tinha sua especificidade e metas diferentes apresentamos os resultados de acordo com cada fase da metodologia; primeiro os resultados da fase exploratória seguindo-se aqueles obtidos na fase empírica.

\section{Resultados da fase exploratória:}

Comecemos por apresentar os resultados da fase exploratória. Relembramos a utilização de entrevistas em grupo, individuais e questionário tipo Likert ocorridos nesta fase.

O questionário tipo Likert foi respondido pela turma 21, cujo resultado encontra-se na Tabela 1.

Tabela 1 - Ranking médio do questionário Likert

\begin{tabular}{lc}
\hline Metodologia de ensino-aprendizagem & Ranking médio \\
\hline Atividades experimentais & 4,5 \\
\hline Atividades investigativas & 3,4 \\
\hline Simulação computacional & 3,3 \\
\hline Videoaula & 3,2 \\
\hline Instrução direta ou explícita & 1,7 \\
\hline Leitura de textos complementares & 1,3 \\
\hline
\end{tabular}

Fonte: $\mathrm{O}$ autor.

O questionário dispunha de 5 categorias; quais sejam: 1 - discordo totalmente; 2 - discordo parcialmente; 3 - sem opinião; 4 - concordo parcialmente e 5 - concordo totalmente. O ranking médio (RM) foi obtido calculando a razão entre a frequência de respostas para cada categoria $(f)$ pelo total de respondentes para cada pergunta $(N)$ :

$$
R M=\sum_{i=0}^{5} \frac{f_{i}}{N}
$$

Por meio deste instrumento avaliamos a atitude dos alunos da turma 21 ante as diversas metodologias de ensino-aprendizagem, por exemplo: qual achavam a mais interessante? Evidentemente que o questionário não avalia aprendizagem, no entanto indica por meio de qual metodologia eles preferem aprender Física.

Pelo que consta na Tabela 1, os alunos da turma 21 apontaram que mediante as atividades experimentais, o ensino de Física tornara-se mais fácil. Em segundo lugar, eles elegeram as atividades investigativas, seguindo-se das simulações computacionais. $O$ ensino diretivo ficou somente em 5 ㅇ lugar, ao passo que as videoaulas ficaram em 40 lugar.

Este resultado pareceu-nos inusitado. A turma 21 é do curso técnico integrado de Informática; este não contém em sua matriz curricular aulas de laboratório de Ciências - Física, Química e Biologia. De fato, aulas de laboratório há apenas as de Informática. Era de se esperar que esta turma optasse pela metodologia de simulações computacionais dado o aspecto vocacional do curso, entretanto isso não aconteceu. 
As razões de o porquê a turma 21 optou pelas aulas experimentais ficará claro ante as análises das entrevistas. Estas, assim como o questionário tipo Likert, serviram para se descobrir qual entre as diferentes metodologias deveríamos utilizar na pesquisa empírica, mas, sobretudo, de determinar qual habilidade cognitiva deveria ser desenvolvida com a pesquisa. Alguns excertos advindos da entrevista com a turma 21 encontram-se no Quadro 1.

Quadro 1 - Excertos da entrevista

\begin{tabular}{|l|c|l|}
\hline Categorias emergentes & Alunos & Transcrições das falas \\
\hline \multirow{4}{*}{$\begin{array}{l}\text { Metodologia fora do } \\
\text { contexto do dia a dia. }\end{array}$} & A1a & Elas são muito focadas em sala de aula (...) \\
\cline { 2 - 3 } & A3a & $\begin{array}{l}\text { Ter a ideia do que vai acontecer no problema (...) a } \\
\text { gente vai pensar em algo que não tá acontecendo (...) }\end{array}$ \\
\cline { 2 - 3 } & A4a & $\begin{array}{l}\text { (...) mais dificuldade porque vai ter que imaginar toda } \\
\text { situação e ... }\end{array}$ \\
\hline \multirow{3}{*}{$\begin{array}{l}\text { Metodologia que exige } \\
\text { da imaginação. }\end{array}$} & A6 & $\begin{array}{l}\text { Com as atividades investigativas a gente tem que } \\
\text { ficar imaginando (...) e na prática é bem mais fácil de } \\
\text { aprender. }\end{array}$ \\
\cline { 2 - 3 } & A1b & $\begin{array}{l}\text { (...) acho que a simulação computacional é mais fácil ... } \\
\text { você tem que imaginar menos que nas outras e tal (...) }\end{array}$ \\
\cline { 2 - 3 } & $\begin{array}{l}\text { (...) foi uma forma melhor de expressar o que estava no } \\
\text { papel ao invés de ficar só imaginando (...) }\end{array}$ \\
\hline $\begin{array}{l}\text { Metodologia } \\
\text { permite o ver e o fazer. }\end{array}$ & A3b & $\begin{array}{l}\text { (..) as pessoas preferem o experimento por que elas tão } \\
\text { vendo o que tá acontecendo e fica mais fácil entender. }\end{array}$ \\
\cline { 2 - 3 } & A4b & $\begin{array}{l}\text { Já no laboratório a gente já não vai mais imaginar, a } \\
\text { gente tá vendo acontecer. }\end{array}$ \\
\hline
\end{tabular}

Fonte: $\mathrm{O}$ autor.

Retirou-se, a esmo, 6 alunos para entrevistá-los. Estes 6 alunos representaram bem o que se apreendeu globalmente sobre a intenção dos alunos para com as diferentes metodologias de ensino-aprendizagem a que foram submetidos na primeira fase da pesquisa.

Viu-se, de acordo com as falas de A1a, A3a e A4a, que as atividades investigativas Ihes pareceram fora do contexto do dia a dia. Pozo e Crespo (2009) ressaltam que uma das grandes dificuldades de aprendizagem em Física deve-se à abstração inerente aos objetos e conceitos científicos (físicos) contidos nas situações físicas.

Um expediente muito comum no ensino das Ciências de grande valor didático-pedagógico é a contextualização (CARVALHO, 2014). Por meio deste expediente atribuem-se características particulares aos conteúdos curriculares estudados em sala de aula; não necessariamente as mesmas que lhe deram origem no aspecto social e histórico. Estas características delimitam o campo de aplicação deste conhecimento, reduzindo-os às possíveis situações vividas pelos alunos (WILLINGHAM, 2011; STERNBERG; STERNBERG, 2016).

Com isso podemos evitar a sobrecarga cognitiva e ainda ajudar no agrupamento do novo conhecimento com aqueles previamente contidos na estrutura cognitiva do aluno (STERNBERG; STERNBERG, 2016; WILLINGHAM, 2011). Esperamos que ao contextualizar uma situação por meio de exemplos concretos e familiares o aluno consiga tornar a situação menos abstrata. 
Pelo que podemos observar no Quadro 1, a contextualização dispensada falhou, mesmo com o cuidado de atender ao que está exposto no parágrafo supra, tanto para as atividades investigativas quanto para a instrução direta. Quando a contextualização não funciona, não se concretizam conceitos científicos e nem se acionam os mecanismos de memória capazes de fazer com que os alunos revivam experiências capazes de ancorar novos conhecimentos (WILLINGHAM, 2011). Se a contextualização falhou, só resta, então, usar a imaginação.

A simulação computacional também foi indicada pelos alunos como uma metodologia que lhes exigia da imaginação, porém em menor grau. Vejamos a fala de A6 ante a comparação da simulação computacional com as atividades investigativas. Em seguida, o aluno A1b, comparando-as à instrução direta complementa dizendo que: com as simulações expressamos melhor o que fica apenas no papel.

Outros termos que se mostraram relevantes foram o ver e o fazer. Estes tiveram próxima relação com aqueles discutidos nos parágrafos supra. Esses termos emergiram diante da caracterização das atividades experimentais usufruindo da máxima do senso comum de que com o ver e o fazer não precisamos imaginar. Para tanto, vejam as falas de $A 3 b$ e A4b no Quadro 1.

Com efeito, ocorre que isto não é verdade!

Vinculam aos conceitos físicos uma gama de objetos (entes) que nunca se mostram diretamente no experimento; e fazer experimento não melhora nossos sentidos, em especial a visão. Em um experimento de cinemática a entidade velocidade média não se mostra; o campo magnético não se visualiza quando colocamos um prego na presença de imã. As imagens produzidas pelas simulações computacionais, idem. Os objetos científicos são construtos da imaginação criativa dos cientistas (ALVES, 2011; REALE, 2002).

A imaginação é uma habilidade imprescindível para aquisição de novos conhecimentos, em especial dos conhecimentos científicos (STERNBERG; STERNBERG, 2016; WILLINGHAM, 2011). Einstein, em uma de suas célebres frases, dizia que a imaginação é mais importante que o conhecimento (WILLINGHAM, 2011). Sempre recrutamos a imaginação ante novas aprendizagens, porém há metodologias que as utilizam mais do que outras (COSENZA; GUERRA, 2011).

O aprender fazendo é uma dimensão importante no ensino de Física na contemporaneidade. Partimos da suposição de que essa dimensão torna o aprendizado mais fácil e mais profundo. Na verdade, este é um dos objetivos mesmo da educação científica (BRASIL, 2002). Existem, todavia, sérias críticas a este modus operandi de se ensinar e de aprender.

Bassoli (2014), por exemplo, chama de mito o aprender ciências fazendo, pois disso implicariam duas situações: (1) o compreender estaria subordinado ao fazer; (2) as aulas experimentais seriam uma espécie de varinha mágica que resolveria todas as dificuldades de aprendizagem. 
Do ponto de vista epistemológico, o aprender fazendo é consequência da cosmovisão empírica e indutiva da ciência (SANTOS, 2013; REALE, 2002) que é transposta diretamente ao contexto escolar. Diante desta cosmovisão o aprendizado só vem depois da experimentação (fazer). Primeiro observamos (ver) para depois construirmos o conhecimento.

Este modelo de aprendizagem vem sendo criticado desde as primeiras reformas educacionais no ensino das Ciências ocorridas no século 20, e esta linha de raciocínio dificilmente levará o aluno a um bom entendimento da Física (Ciências) e de seu processo de construção e validação (TRÓPIA, 2011).

Pontuamos, em síntese, as seguintes conclusões ante as falas dos alunos da turma 21:

1. Os alunos tiveram dificuldades em elaborar mentalmente situações não vivenciadas por eles. Assim, as categorias que descrevem bem o grupo entrevistado do ponto de vista de habilidades cognitivas, em uma primeira codificação foram: contextualizar, imaginar, abstrair, aprender vendo, aprender fazendo e aprender colaborativamente.

2. As categorias atividades experimentais e atividades de discussão conseguem aglutinar as preferências dos alunos no aspecto metodologia de ensino; primeiro porque eles gostam de aprender fazendo e sentem-se motivados a trabalhar em equipe; segundo porque a discussão em sala de aula também Ihes facilitou a aprendizagem.

3. Pelo exposto na base teórica deste ensaio, já indicamos a relação entre imaginação, abstração e contextualização. E como vimos da definição de pensamento abstrato adotada aqui, não separamos a imaginação do pensamento abstrato.

Dada a faixa etária dos alunos da turma 21, sua aparelhagem cognitiva já está pronta para lidar com situações complexas operando com o raciocínio abstrato. Isto significa que o adolescente pode distinguir o real do imaginativo, bem como projetar possibilidades do real pela imaginação (CLOUTIER; DRAPEAU, 2012). Ter esta capacidade, porém, é diferente de ser habilidoso ao utilizá-la.

Isso posto, em uma segunda codificação - que consistiu em aglutinar as categorias da Tabela 2 em categorias mais amplas - concluímos que a habilidade do pensamento abstrato foi a habilidade-fim a se desenvolver. Resta então indicar diante do resultado das entrevistas e da escala tipo Likert, qual metodologia utilizar. Pelo que consta em Carvalho (2014) e Suart et al. (2010), entendemos que o laboratório aberto é a metodologia mais indicada para realizar tal atividade.

\section{Resultados da fase empírica e a atividade de laboratório aberto}

A turma 21 já havia realizado aulas de laboratório tradicional com experimentos sobre termodinâmica, mas ainda não havia terminado o cronograma sobre transmissão de calor. Além disso, esta turma foi submetida a três ciclos de atividades de laboratório aberto e estes resultados dizem respeito ao terceiro deles.

Tivemos como ponto de partida a euforia apresentada pelos alunos após assistirem a um filme na aula de Biologia sobre o reino animal que dava ênfase às aves. Assim, lançamos a seguinte situação-problema para a turma: Explique como e qual é o processo físico que permite a planagem dos pássaros? 
Cabe o esclarecimento de que esta foi uma situação-problema não trivial para os alunos da turma 21 , pois o conteúdo de transmissão de calor ainda não havia sido finalizado. Logo, tem-se uma questão aberta devido ao conhecimento aproximado dos alunos sobre o tema. A convecção, que é um dos mecanismos responsáveis pela planagem dos pássaros, ainda não havia sido estudada.

Um recorte feito neste ensaio consiste em observar, apenas, a parte térmica do fenômeno de planagem. Isto é relevante, pois é um fenômeno bastante complexo, em especial se voltarmos os olhos para o seu aspecto mecânico, que envolve a movimentação da massa de ar em direção ao pássaro, a massa de ar movimentada pelo pássaro e da interação deste com as massas de ar levando em conta sua aerodinâmica.

Como veremos logo mais à frente, haverá rápidas explanações sobre questões mecânicas, mas nada que satisfaça o perito, especialista, o licenciado em Física, tampouco, no entanto foram suficientes para a negociação com os alunos. Com efeito, não cabe aqui se deter nestes aspectos técnicos devido à natureza desta investigação, bem como dos sujeitos participantes.

$\mathrm{Na}$ aula 1 solicitamos, então, que a turma se dividisse em grupos com 4 alunos e indicassem, num primeiro momento, quais seriam as variáveis que controlam o voo dos pássaros durante a planagem. O objetivo disso foi buscar por evidências empíricas sobre a manifestação da habilidade cognitiva de análise, habilidade essa recrutada para a elaboração do pensamento abstrato.

Na Tabela 2 vemos a variável mais indicada pela turma: o grande aquecimento da superfície ( 9 vezes), o que está fisicamente incorreto. 0 mecanismo físico - do ponto de vista termodinâmico - que torna possível a planagem é o gradiente ou diferença de temperatura entre a superfície e a atmosfera. Daí surge a convecção atmosférica (PIETROCOLA et al., 2011; NUSSENZVEIGH, 2002). Sete (7) equipes apontaram corretamente esta variável.

$\mathrm{O}$ ar quente, próximo à superfície, torna-se mais leve e sobe, e, consequentemente, torna-se menos denso ao se aquecer (PIETROCOLA et al., 2011; NUSSENZVEIGH, 2002), fazendo com que próximo à superfície a densidade torne-se menor, mas a baixa densidade do ar próximo à superfície só foi indicada como variável responsável pela planagem três vezes.

Tabela 2 - Variáveis que controlam o voo do pássaro

\begin{tabular}{lc}
\hline Variáveis & Frequência \\
\hline Anatomia do pássaro. & 5 \\
\hline Temperatura do ar. & 7 \\
\hline Diferença de temperatura entre atmosfera e a superfície. & 7 \\
\hline Grande aquecimento da superfície. & 9 \\
\hline Diferença de pressão atmosférica. & 2 \\
\hline Velocidade vertical do vento. & 6 \\
\hline Baixa densidade do ar próximo & 3 \\
à superfície. & \\
\hline
\end{tabular}


A velocidade vertical foi indicada 6 vezes. Faz algum sentido supor, uma vez que haja massa de ar subindo, que ela tenha, certamente, uma velocidade maior que as demais, no entanto precisamos, para tanto, uma descrição mecânica para o fenômeno da convecção por meio do gradiente (diferença) de pressão atmosférica (PIETROCOLA et al., 2011; NUSSENZVEIGH, 2002); não obstante, esse dito mecanismo foi indicado duas vezes, apenas.

A equação dos gases ideais - que se relaciona às variáveis de pressão, temperatura e volume - já era conhecida dos alunos, mesmo assim eles não conseguiram utilizá-la para indicar que a diferença de pressão é uma variável relevante para descrever a planagem.

Ante as atividades de investigação há de se observar que não podemos respondê-las deliberadamente, mas podemos conduzir (guiar) os alunos a obter as respostas fazendo as mediações necessárias. O modelo pedagógico construtivista prevê que assim o seja. Foi o que fizemos. Iniciamos uma discussão com todos os alunos de modo que foi consensual de que a resposta viria pelo estudo dos processos de trocas de calor. Esta foi a conclusão da discussão com os alunos.

De outro modo, não é este o caso da explicação física mais precisa do fenômeno, haja vista que temos o aspecto mecânico relativo à planagem, seja pelo estudo do movimento ou pela aerodinâmica do corpo do pássaro. Esta dimensão, todavia, não foi levada em consideração aqui neste ensaio.

Solicitamos, então, que os alunos propusessem três hipóteses explicativas para o fenômeno da planagem e entregassem-nas. Os resultados encontram-se dispostos no Quadro 2.

Quadro 2 - Hipóteses explicativas para planagem feitas pelas equipes da turma 21

\begin{tabular}{|c|l|l|}
\hline Grupos & \multicolumn{1}{|c|}{ Hipóteses explicativas } & Adequação \\
\hline A & $\begin{array}{l}\text { 1.(...) sua anatomia proporciona esta atividade. } \\
\text { 2. Sua anatomia combinada com a densidade. }\end{array}$ & Não coerente \\
\hline B & $\begin{array}{l}\text { 1. (...) São correntes de ar ... } \\
\text { 2. Sacos de ar ascendentes. } \\
\text { 3. Por causa da massa de ar quente... }\end{array}$ & Coerente \\
\hline C & $\begin{array}{l}\text { 1. Devido à estrutura corporal facilitada. } \\
\text { 2. (...) por causa da densidade do ar. }\end{array}$ & Pouco coerente \\
\hline D & $\begin{array}{l}\text { 1. (...) pela diferença de temperatura e de densidade do ar. } \\
\text { 2. Devido à estrutura corpórea da ave (...) }\end{array}$ & Coerente \\
\hline E & $\begin{array}{l}\text { Devido ao calor que sobe levando o pássaro, que é menos denso que o ar. } \\
\text { 1. Pelas diferenças de temperatura do ar. } \\
\text { 2. Algumas estruturas fisiológicas internas e externas (...) }\end{array}$ & Não coerente \\
\hline $\mathrm{G}$ & $\begin{array}{l}\text { 1. Sacos de ar. } \\
\text { 2. Massa de ar quente ascendente. }\end{array}$ & Pouco coerente \\
\hline $\mathrm{H}$ & $\begin{array}{l}\text { 1. É a convecção utilizando as termas que são bolhas de ar quente } \\
\text { ascendentes. } \\
\text { 2. Aerodinâmica do corpo do pássaro. }\end{array}$ & Coerente \\
\hline I & $\begin{array}{l}\mid c * * * * * \\
\text { J }\end{array}$ & $* * * * *$ \\
\hline
\end{tabular}


Os grupos I e J, como se vê logo de início, no quadro 2, não atenderam à nossa solicitação. Por outro lado, os demais o fizeram com empenho. Os termos mais utilizados pelos grupos para descrever o voo do pássaro foram: anatomia do pássaro (5 vezes) e a convecção (7 vezes). Observa-se que o termo convecção propriamente só foi utilizado pelo grupo $H$ uma única vez; no entanto os demais valeram-se de termos sinônimos para denotar o mesmo fenômeno atmosférico, os quais foram: ar ascendente e sacos de ar quente, como nos grupos $\mathrm{B}(1,2)$ e $\mathrm{G}(1,2)$; o calor que sobe e termas em $\mathrm{E}$ e $\mathrm{H}$.

A diferença de temperatura foi utilizada duas vezes pelos grupos $\mathrm{D}(1)$ e $\mathrm{E}$, contudo não ficou explícito, em ambos, de onde vinha esta diferença de temperatura. A densidade do ar apareceu nas hipótese dos grupos $A(2)$ e $C(2)$, mas já explicamos que, na verdade, o empuxo acontece devido à diferença de densidade - não pela densidade do ar de per se.

Foi assim que nas hipóteses elaboradas por quatro equipes apareceu, ao menos uma vez, uma variável que realmente descrevesse o fenômeno da convecção de modo que foram classificadas como hipóteses coerentes.

Os demais grupos oscilaram entre hipóteses pouco coerentes e não coerentes. Estas focaram-se na aerodinâmica do pássaro, ao passo que aquelas não explicaram, exatamente, qual é o fenômeno físico em questão. De modo geral, pensamos que a elaboração da hipótese ficou comprometida.

Em síntese, dado que os alunos indicaram as variáveis que controlam o voo do pássaro e propuseram, em sua maioria, hipóteses coerentes ou pouco coerentes, vemos isto como um indício de que o laboratório aberto favoreceu o desenvolvimento da habilidade cognitiva de análise.

Após esta etapa de elaboração de hipóteses, solicitamos aos alunos da turma 21 que dividissem as tarefas que seriam empregadas para a solução da situação-problema. Cada membro do grupo deveria ficar com determinada tarefa: pesquisar o assunto teórico, buscar por alternativas viáveis para realização do experimento, quais materiais seriam utilizados, como será a coleta de dados, entre outras. Além disso, que observassem que a solução do problema deveria conter fatos advindos do experimento - que seria realizado na aula seguinte.

$\mathrm{Na}$ aula 2 passamos diretamente para a realização do experimento no laboratório didático da instituição. Pelo que foi entregue pelas equipes, os materiais que seriam utilizados no experimento foram: velas, fósforos, hélice de metal, uma haste para anexar a hélice, cronômetro (ou timer do celular) e régua. Notou-se que houve convergência dos materiais utilizados pelos diferentes grupos, isso pois eles interagiram ao longo da semana que antecedeu esta aula. O subsídio teórico foram os livros de Física da biblioteca da instituição e de alguns sites e vídeos da Internet, mas não sabemos informar quais foram esses materiais especificamente.

Grosso modo o experimento consistiu em fazer uma hélice de metal leve (alumínio) e rotacionar assim que as camadas de ar abaixo dela estivessem aquecidas.

Momentos antes da realização do experimento alunos dos grupos A, C e G, fizeram a seguinte pergunta: Que altura devemos posicionar a vela abaixo da hélice? 
Não respondemos a esta questão, mas dissemos o seguinte: (...) gostaríamos que vocês pensassem um pouco mais para concluírem se a altura é uma variável importante para a realização do experimento ou não!

Desta forma, os alunos, ao realizar o experimento, fizeram-no posicionando a vela a diferentes alturas, e cronometravam o tempo em que se iniciava a rotação da haste para cada altura. Fizeram-no várias vezes com diferentes membros intercambiando as tarefas entre si.

Na terceira aula aconteceu a socialização das conclusões dos grupos para a situação-problema e dialogamos (mediação) com a turma procurando fazê-los extrapolar seus resultados para diversas situações cuja explicação poderia ser descrita pelo fenômeno da convecção térmica. As soluções apresentadas pelos grupos da turma 21 constam no Quadro 3.

Mais uma vez o grupo J não completou a tarefa. Apesar de o grupo I não ter elaborado a hipótese para o problema, fez a investigação, nos entregou as anotações sobre o planejamento do experimento e realizou-o sem dificuldades.

Quadro 3 - Resoluções dos alunos para situação-problema

\begin{tabular}{|c|c|c|}
\hline Grupos & Resposta à situação-problema & Adequação \\
\hline$A$ & $\begin{array}{l}\text { (...) devido ao processo de convecção as aves percebem que uma corrente } \\
\text { ascendente (térmica) está ocorrendo em determinado ponto. Então, as aves } \\
\text { vão subindo por este ponto até uma determinada altura ganhando energia } \\
\text { potencial...nesse processo elas [aves] não gastam energia. }\end{array}$ & $\begin{array}{l}\text { Pouco } \\
\text { coerente }\end{array}$ \\
\hline B & $\begin{array}{l}\text { Após algum tempo que o sol aquece a superfície da Terra, esta aquecerá o ar } \\
\text { logo acima. O ar que está logo acima da superfície tende a ficar quente e como } \\
\text { o ar quente é menos denso ele sobe, e quanto maior a diferença de temperatura } \\
\text { entre o ar e a Terra, mais intensa é a convecção. É assim que as aves planam sem } \\
\text { gastar energia; é uma carona grátis da natureza. }\end{array}$ & Coerente \\
\hline C & $\begin{array}{l}\text { As aves usam as termas ou térmicas para planarem no ar. A superfície aquecida } \\
\text { do nosso planeta faz com que o ar mais quente suba, uma vez que é menos } \\
\text { denso (...). Cada parcela de ar quente sobe até determinada altura e a natureza } \\
\text { se aproveita delas. Essa altura pode se tornar maior dependendo do tempo de } \\
\text { aquecimento da superfície. As aves percebem esta corrente ascendente de ar e } \\
\text { se aproveitam dela para planarem. Esta terma é mais intensa entre } 12 \text { e } 14 \text { horas. }\end{array}$ & Coerente \\
\hline D & $\begin{array}{l}\text { As aves utilizam as termas para planarem (...) a superfície aquecida pela manhã } \\
\text { toda [tempo] do nosso planeta faz com que o ar mais quente suba, uma vez que } \\
\text { o ar mais quente é menos denso que o ar mais frio. } \\
\text { (...) a natureza se aproveita delas [termas]. } \\
\text { As aves percebem uma corrente ascendente acontecendo (...) }\end{array}$ & Coerente \\
\hline$E$ & $* * * * *$ & $* * * * *$ \\
\hline $\mathrm{F}$ & $\begin{array}{l}\text { (...) primeiro a gente precisa saber o que é uma térmica: o processo de formação } \\
\text { de nuvens (...) que são parcelas de ar quente que sobem, já que são menos densas. } \\
\text { O sol aquece a superfície da Terra após as } 6 \text { horas da manhã, esta superfície } \\
\text { aquece o ar acima dela que fica manos denso, e, então, sobe. Do mesmo jeito } \\
\text { que os planadores, as aves se aproveitam das termas; é muito interessante. }\end{array}$ & $\begin{array}{l}\text { Pouco } \\
\text { coerente }\end{array}$ \\
\hline G & $\begin{array}{l}\text { De acordo com os mecanismos de transferência de calor: a convecção ocorre } \\
\text { como consequência de diferenças de densidade do ar. Quando o calor é conduzido } \\
\text { da superfície relativamente quente para o ar subjacente, este ar torna-se mais } \\
\text { quente que o ar vizinho. O ar quente é menos denso que o ar frio de modo que } \\
\text { o ar mais frio e denso desce e força o ar mais quente e menos denso a subir. O ar } \\
\text { mais frio é então aquecido pela superfície e o processo é repetido. } \\
\text { De acordo com o experimento é possível perceber a relação entre o voo dos } \\
\text { pássaros e o movimento das hélices. As termas só se formam após a diferença } \\
\text { de temperatura tornar-se considerável. }\end{array}$ & Coerente \\
\hline
\end{tabular}




\begin{tabular}{|c|l|l|}
\hline $\mathrm{H}$ & $\begin{array}{l}\text { (....) Tendo em vista que a convecção se dá através do transporte de matéria, a } \\
\text { diferença de densidade e a ação da gravidade, podemos concluir que as aves se } \\
\text { utilizam desse meio de propagação para poderem planar a uma determinada } \\
\text { altura, utilizando a aerodinâmica de seu corpo a um determinado tempo sem } \\
\text { gastar energia. }\end{array}$ & Coerente \\
\hline $\mathrm{I}$ & Os pássaros utilizam as termas para subirem. & $\begin{array}{l}\text { Pouco } \\
\text { coerente }\end{array}$ \\
\hline $\mathrm{J}$ & \multicolumn{1}{|c|}{$* * * *$} & $* * * *$ \\
\hline
\end{tabular}

Fonte: $\mathrm{O}$ autor.

Note-se que as resoluções classificadas como coerentes trouxeram consigo a descrição do fenômeno físico e a informação da variável tempo, cuja importância só se observou com o experimento, ou seja: conclusões baseadas em evidência empírica - vide Quadro 3.

Logo entendemos que para os grupos apresentarem suas resoluções para a situação-problema, os alunos deveriam ser capazes de organizar uma resposta final, que de certo modo deveria estar relacionada, não somente com o que foi lido na pesquisa bibliográfica, mas, também, com os achados do experimento. Concluímos, portanto, que os alunos fizeram uma sintese, que é uma das habilidades cognitivas que inere ao pensamento abstrato. Esta é a habilidade cognitiva que estávamos à procura por indícios de sua manifestação por meio do laboratório aberto.

Diante do exposto, temos indícios de que pela atividade investigativa de laboratório aberto foi possível aos alunos desenvolverem a habilidade cognitiva de análise (Tabela 2) e de síntese (Quadro 3); ambas são recrutadas para a composição da habilidade que denotamos por pensamento abstrato no contexto desta pesquisa.

\section{CONSIDERAÇÕES FINAIS}

Neste ensaio apresentamos resultados preliminares de uma tese de Doutoramento sobre o desenvolvimento do pensamento abstrato no ensino de Física por meio de atividades investigativas do tipo laboratório aberto.

O laboratório aberto é uma metodologia de ensino-aprendizagem que depende sobremaneira do aluno. Algumas dimensões como motivação, engajamento e a responsabilidade consigo mesmo e com os colegas são mandatórias para o bom desenvolvimento do laboratório aberto. E assim o foram, de fato.

Foi muito importante, portanto, investir em uma relação de confiança (afetividade) professor-pesquisador e aluno, pois o laboratório aberto exige muita conversa, muito esclarecimento de onde se pretende chegar e do que podemos aprender ao longo de toda execução da atividade investigativa.

Para evitar que caíssemos numa rotina pouco proveitosa de atividades experimentais, incluindo-se não apenas o laboratório aberto, mas, também, o laboratório tradicional, recomendamos que os professores façam essa atividade a intervalos de tempo espaçados. Isto nos ajudou bastante, pois mesmo o aluno não motivado - que trabalhou sem prazer - fê-lo com diligência e responsabilidade para com o grupo. 
Com efeito, foi observado que, o que se perdeu em motivação, tornou-se acréscimo em responsabilidade; e acreditamos que educar para a responsabilidade possibilita colher bons frutos em médio e longo prazos nas dimensões social, política e econômica.

Uma segunda recomendação advém da máxima cognitivista de que o desenvolvimento de habilidades não deve preceder o conhecimento factual. Isto foi importante neste ensaio por dois motivos: (1) evitamos colocar os alunos em uma situação de terem de aprender sobre um problema ao mesmo tempo que pretendem resolvê-lo; (2) apesar de que as habilidades se desenvolvem praticando-as, é importante que já tenhamos um conhecimento mínimo que guie nossa prática; do contrário podemos entrar num ciclo de tentativa e erro que é contraproducente no contexto educacional.

Ante o não atendimento destas condições incorremos o risco de transformar a atividade didática em algo acima das capacidades do aluno, tendo um grande efeito desmotivador. É prerrogativa do modelo construtivista que o aluno encontre seu próprio meio para resolver problemas; nisto consiste a ação construtivista. Essa ação, no entanto, precisa ser algo em que o aluno consiga trabalhar, que saiba como fazê-la ao menos em aproximação. Logo, importa sim oferecer subsídios para que o aluno possa resolver a situação-problema proposta.

A terceira e última recomendação - vem como consequência das anteriores - é não submeter alunos sem vivência em aulas práticas de laboratório a praticarem atividades investigativas de laboratório aberto sem antes lhes darmos condições para fazê-las. Esta metodologia exige muito preparo, tanto de nossa parte quanto dos alunos. As experiências vividas com alunos noviços não foram interessantes num primeiro momento, em especial no quesito autonomia; pois foi necessário tanta intervenção que, a nosso ver, comprometeu o grau de liberdade que o aluno deveria ter para desenvolver a investigação.

Finalmente, esperamos que este ensaio traga alguma contribuição teórica no que diz respeito ao desenvolvimento da habilidade de pensamento abstrato, e, também, no aspecto metodológico, haja vista que trazer para a dimensão empírica os pressupostos das atividades investigativas de laboratório aberto - que em um primeiro momento parecem simples - mostrou-se algo bastante complicado, exigindo bastante planejamento e controle da execução das atividades, até que, de fato, a turma 21 estivesse apta para trabalhar com laboratório aberto e pudéssemos fazer a coleta de dados para verificar a tese defendida neste ensaio.

\section{REFERÊNCIAS}

ALVES, Alaôr Caffé. Lógica: pensamento formal e argumentação. 5. ed. São Paulo: Quartier Latin, 2011. BASSOLI, Fernanda. Atividades práticas e o ensino-aprendizagem de ciências: mitos, tendências e distorções. Ciência e Educação, v. 20(3), 2014.

BECKER, Fernando. Epistemologia do professor: o cotidiano da escola. 13. ed. Petrópolis: Vozes, 2013. BERGMANN, Jonathan; SAMS, Aron. Sala de aula invertida: uma metodologia ativa de aprendizagem. 1. ed. Rio de Janeiro: LTC, 2016.

BORGES, Antônio Tarcísio. Novos rumos para o laboratório escolar de ciências. Caderno Brasileiro de Ensino de Física, v. 19(3), 2002.

BRASIL. Ministério da Educação. Secretaria de Educação Média e Tecnológica. Parâmetros Curriculares Nacionais $+(P C N+)-$ Ciências da Natureza e suas Tecnologias. Brasília: MEC, 2002. 
CARVALHO, Anna Maria Pessoa de (org.). Calor e temperatura: um ensino por investigação. 1. ed. São Paulo: Livraria da Física, 2014.

CHEVALLARD, Yves. La transposición didáctica: del saber sábio al saber enseñado. Argentina: Lá Penseé Sauvage, 1991.

CLOUTIER, Richard; DRAPEAU, Sylvie. Psicologia da adolescência. Petrópolis: Vozes, 2012.

COSENZA, Ramon M.; GUERRA, Leonor R. Neurociência e educação: como o cérebro aprende. Porto Alegre: Artmed, 2011.

CRATO, Nuno. O eduquês em discurso direto: uma crítica da pedagógica romântica e construtivista. 11. ed. Lisboa: Gradiva, 2010.

FERREIRA, Luiz Henrique et al. Ensino experimental de química: uma abordagem investigativa contextualizada. Química Nova na Escola, v. 32(2), 2010.

GASPAR, Alberto. Atividades experimentais no ensino de física: uma nova visão baseada na teoria de Vygotsky. 1. ed. São Paulo: Livraria da Física, 2014.

GAUTHIER, Clermont et al. Ensino explícito e desempenho dos alunos: a gestão dos aprendizados. Petrópolis: Vozes, 2011.

GIL, Antônio. Como elaborar projetos de pesquisa. 5. ed. São Paulo: Atlas, 2010.

JAPIASSÚ, Hilton; MARCONDES, Danilo. Dicionário de filosofia. 3. ed. Rio de Janeiro: Zahar, 2001.

KASSEBOEHMER, Ana Claúdia; FERREIRA, Luiz H. Elaboração de hipóteses em atividades investigativas em aulas teóricas de química por estudantes de ensino médio. Revista Química Nova na Escola, v. 35, n. 2, 2013.

LÜDKE, Menga; ANDRÉ. Marli, E. D. Pesquisa em educação: abordagens qualitativas. 2. ed. Rio de Janeiro: GEN, 2015.

MUNFORD, Danusa; LIMA, Maria Emília. Ensinar ciências por investigação: em quê estamos de acordo? Revista Ensaio, v. 9(1), 2007.

NUSSENZVEIGH, Moysés Herch. Curso de física básica. 4. ed. São Paulo: Edgar Blucher, 2002. Vol. 2.

POZO, Juan Ignácio; CRESPO, Miguél Angel G. Aprendizagem e o ensino de ciências: do conhecimento cotidiano ao conhecimento científico. 5. ed. Porto Alegre: Artmed, 2009.

PIETROCOLA, Maurício et al. Física em contextos. 1. ed. São Paulo: FTD, 2011. Vol. 2.

REALE, Miguel. Filosofia do direito. 20. ed. São Paulo: Saraiva, 2002.

RODRIGUES, Bruno A.; BORGES, Tarcísio A. Ensino por investigação: reconstrução histórica. In: ENCONTRO DE PESQUISA DE ENSINO DE FÍSICA, 11., 2008. Paraná, 2008.

SAMPIERI, Roberto Hernández et al. Metodologia da pesquisa. 5. ed. São Paulo: Penso, 2013.

SANTOS, Mário Ferreira dos. Filosofia e cosmovisão. São Paulo: É realizações, 2013.

SANTOS, Mário Ferreira dos. Filosofias da afirmação e da negação. São Paulo: É realizações, 2017.

SOUZA, Nelson P. C.; VALENTE, José A. S. Aprendizagem completamente dirigida aprendizagem minimamente dirigida. Ciências e Cognição, v. 19(1), 2014.

STERNBERG, Robert J.; STERNBERG, Karin. Psicologia cognitiva. 2. ed. São Paulo: Cengage Learning, 2016. SUART, Rita de Cássia et al. A estratégia de laboratório aberto para construção do conceito de temperatura de ebulição e a manifestação de habilidades cognitivas. Química Nova na Escola, v. 32(3), 2010.

THIOLLENT, Michel. Metodologia da pesquisa-ação. São Paulo: Cortez, 2011.

TRÓPIA, Guilherme. Percursos históricos de ensinar ciências através de atividades investigativas. Revista Ensaio, v. 13(1), 2011.

VEIT, Eliane Ângela et al. Ilustrando a 2a lei de Newton no século XX. Revista Brasileira do Ensino de Física, v. 24(2), 2002.

WILCOX, Bethany R.; LEVANDOWSKI, Heather J. Developing skills versus reinforcing concepts in physics labs: insight from a survey of students' beliefsabout experimental physics. Physical Review Physics Education Research, v. 13(1), 2017.

WILLINGHAM, Daniel T. Por que os alunos não gostam de escola? Respostas da ciência cognitiva para tornar a sala de aula mais atrativa. 1. ed. Porto Alegre: Artmed, 2011.

ZÔMPERO, Andrea de Freitas; LABURÚ, Carlos Eduardo. Atividades investigativas no ensino de ciências: aspectos históricos e diferentes abordagens. Revista Ensaio, v. 13(3), 2011. 